\title{
SMART INTEGRATION OF EVALUATION ACTIVITIES IN THE FRAMEWORK OF PHYSICAL OPTICS MOOC (MOOC UCA-002) OF THE MUN PLATFORM
}

\author{
S. Machwate ${ }^{1}$, I.Mekkaoui Alaoui ${ }^{1, *}$ \\ ${ }^{1}$ Trans ERIE, Cadi Ayyad University - Faculty of Sciences Semlalia. BP.: 2390 - Marrakech, Morocco- s.machwate@uca.ma, \\ mekkaoui@uca.ma
}

KEYWORDS: MOOC, physical optics, learner, instructional design, evaluation.

\begin{abstract}
:
The MOOC of physical optics of the Morocco Digital University platform is intended mainly for students of the Moroccan universities and engineering schools. The first session took place during the period March-June 2019. This MOOC includes the physical optics program of the license in physical sciences. It contains pedagogically scripted videos, documents for integrated reading or download, audiovisual presentations of practical experiences, links to digital simulations, exercises, and evaluations. The proposed assessment is carried out in three stages. A reflexive self-assessment at the end of each video capsule. A formative/summative evaluation at the end of the week. A summative evaluation covering the entire content. Students of the Faculty of Sciences Semlalia, who followed the MOOC completely or in part, were able to improve their results of the final face-to-face exam. Learners, who have obtained an overall grade higher than $60 \%$, can obtain a certificate of success of this MOOC issued by a national entity.
\end{abstract}

\section{INTRODUCTION}

The advent of MOOCs in the higher education spectrum is booming. Cadi Ayyad University (UCA) is among the pioneers in Morocco to take an interest in and produce digital courses online and on the platforms of its various institutions. The UCA has a learning platform (www.mooc.uca.ma), based on massive open online courses (MOOCs). It is made available to the public but mainly intended for University students (Idrissi Jouicha et al., 2020).

Massive Open Online Courses (MOOCs) are part of the large family of Open Educational Resources (OER) and are open to all learners through the web (Gasevic et al., 2014; McGreal et al., 2013). A MOOC usually contains videos (capsules), course manuals, multiple-choice questions (MCQ), comprehension activities, simulations, forums, assessments, and a certificate for those who have exceeded a certain level of evaluation threshold (Bakki et al., 2017).

The MOOC of physical optics, presented in this work, is part of the "Maroc Université Numérique" platform (MUN, https://www.mun.ma/). It is a national platform managed by the Moroccan Ministry of Higher Education in Morocco. The MOOC contains four parts of almost the same hourly volume (2 weeks per part). In each part, there is a pdf course document, video capsules of each concept in the course, exercises in the form of multiple-choice questions (MCQ), assessment exercises, and practical presentations (experiences recorded in the form of video capsules in the laboratory of practical work). Some links to computer simulations were proposed to clarify situations. In each chapter, a FAQ (Frequently Asked Questions) is set up to answer learners' queries by pairs or by the pedagogical staff. To follow and understand the parts of this course, prerequisites in geometrical optics and undergraduate mathematics are required.

The physical optics MOOC can be used to perform blended or hybrid learning. There are several definitions of hybrid learning
(BÉDARD et al., 2017). A hybrid course is designed so that some class hours are replaced by equally important online activities. This means that the classroom and online parts of a course are complementary. These parts must be thoughtfully combined so that the learner and the teacher (teachers) are coordinated and synchronized on the course purposes. For a course to be hybrid, 20 to $80 \%$ of its content must be replaced by online activities. It is a wide range of possibilities to adapt to different types of education (natural and medical sciences, physical and mathematical sciences, humanities, engineering, etc.)

The structure of the hybrid courses varies in order to adapt to the learning environment. It also depends on the content of the lessons, the preferences of the teacher or teaching staff, the needs of students (learners), the distribution of online and classroom activities, etc (Vaughan, Cleveland-Innes, \& Garrison, 2013). So there is flexibility, it is sometimes called blended and/or flexible learning. The challenges associated with designing a hybrid course are found in the distribution of online and classroom activities in order to find the right balance (Peraya et al., 2014).

\section{RELATED WORKS:}

The use of a MOOC to foster one knowledge is wildly expending in the learning and training world. The trends of using this kind of artifacts are increasing exponentially. One idea to use these tools has been defined as a smart way to develop teaching and learning practices in and outside the classroom (Pisha \& Coyne, 2001). In many cases, the learning outcomes reveal to be increased when beneficiating from existing MOOCs and adopting them as Small Private Online Courses (SPOCs) (Alario-Hoyos et al., 2017; Hudson et al., 2016). These last were considered more controlled when it comes to specific small groups of learners (Guo, 2017).

Corresponding author 
Evaluation of MOOCs was generally based on perceptions of teachers or learners (Callejo Gallego \& Agudo Arroyo, 2018). The models put on practice are analyzed regarding the answers to surveys or questionnaires. The experience showed that other complex parameters have to be taken into account to set a more rigorous evaluation. Chapman et al., described how MOOC initiatives are complex adaptative systems. They argue that the engagement of learners, the monitoring approach, the kind of pedagogical material or platform, the workload for both teachers or learners, and other parameters make the learning outcomes unpredictable and presented unpredictable challenges (Chapman et al., 2016).

Other MOOCs experimented in a face-to-face course, such as an on classroom MOOC, have shown good pedagogical contribution. It has been noted that the effect of automatic assessment was important when providing real-time feed-back for all learners especially for large groups (Brita-Paja et al., 2019).

In this sight, the study presented in this work tries to answer the question of "how using MOOC outside the classroom as second-course support for students could be profitable for fostering course outcomes?" We describe the model of the MOOC of Physical Optics used, and we give the results obtained comparing the achievement of activities on the MOOC and marks obtained in the in-classroom final exam.

\section{METHODOLOGY}

In this study, we describe the setting of a MOOC of Optical Physics first designed to the Moroccan students of the Faculty of Sciences of the second year of Physics Studies of the Moroccan universities and those of the Faculty of Sciences Semlalia in particular. We evaluate the content and the learning outcomes of learners based on the evaluation activities, and we give some reflection areas for improvement for a future experience.

\section{STRUCTURE AND CONTENT OF THE MOOC OF PHYSICAL OPTICS}

\subsection{Advantages of digital}

Technology is used primarily to support education. But in recent years technology has exerted an increasing influence on the basic activities of university education and even secondary and primary education (Bates \& Sangra, 2011). The information can be accessible by anyone at any time, which encourages distance learning. This is possible if we assume that, a computer, smartphone, tablet, etc. and an internet connection are available. Collaboration is facilitated as well as the abolition of geographic distance. The innovative creation of new forms of active pedagogy, of hybrid training devices, and the opportunities for open learning are real and possible (Schuwer et al., 2015).

\subsection{Introduction of the MOOC of physical optics}

Following a call for proposals launched by the Moroccan Ministry of Higher Education, the MOOC of physical optics was chosen to be integrated into the new ministerial strategy that aims to share good online teaching practices for the benefit of Moroccan students.

MOOCs are open for all learners across the web, while SPOCs are open, by invitation, for a limited number of participants. The learners targeted by the MOOC of physical optics are students of physical sciences and engineering as well as amateurs of optics and astronomy. The 1st session was opened from March 25 to June 30, 2019. Registration for this session was relatively low (215 learners) due to the low visibility and communication of the central team (This was the first MOOC on the MUN platform). The initial trend in MOOC registration and completion is generally weak for platforms with limited visibility (Jordan, 2014). The 2nd session is open from March 10 to June 30, 2020. The Registration for the second session is much better than the first one (775 learners). Results and feedback from the second session will be published after the inclass exams of September 2020 (Delayed due to COVID-19).

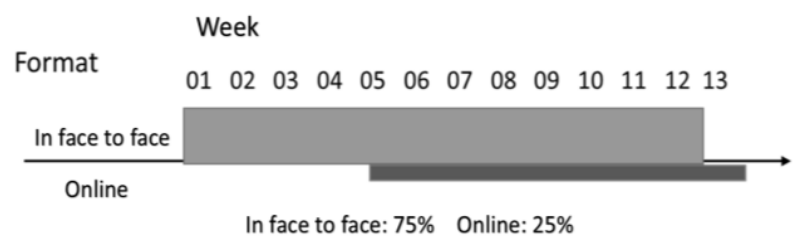

Figure 1: Distribution of the physical optics course in session 1, Spring 2019.

The course takes place over 7 weeks of lessons, plus a zero week of introduction and another week of the final evaluation. The total is 9 weeks. Figure 1 is the distribution of the physical optics course at Cadi Ayyad University (Session 1, Spring 2019). $75 \%$ face to face and $25 \%$ online.

\subsection{Structure}

Figure 2 shows the overall structure of the MOOC. The first week, "Week 0", is the course presentation. It contains an explanatory document and a prerequisite test. The purpose of this test is, on the one hand, to refresh the memory of the tools necessary for the rest of the course, and on the other hand to allow the non-student audience to position themselves before starting the course.

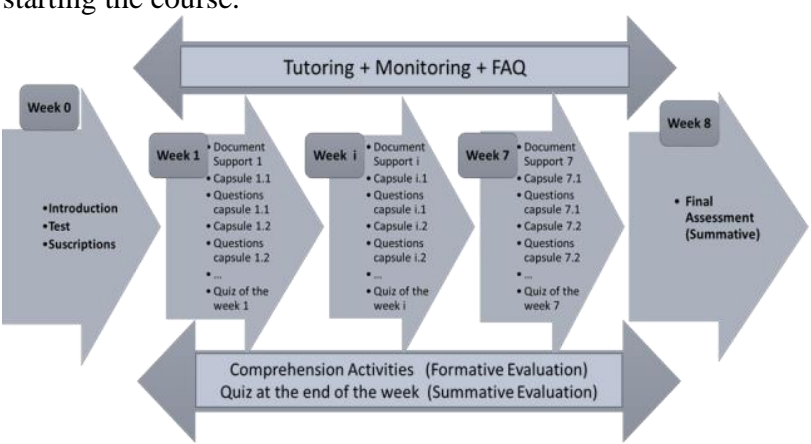

Figure 2: Structure of the Physical Optics MOOC

From week 1 to week 7 , the course is presented in the same way: documents relating to each week, explanatory video capsules, direct comprehension questions, and a weekend quiz that will be counted as an evaluation of the work carried out during the week. During these seven weeks of lessons, learners are accompanied by tutors/facilitators and have access to a FAQ to guide them in case of recurring questions. Week 8 is kept to the final evaluation that consists of three exercises on the three main parts of the course.

\subsection{Content}

The physical optics MOOC is made up of the same teaching material as the face-to-face course. A PDF course support in place of the handout (Ech-chamikh \& Mekkaoui Alaoui, 2013), 
video capsules to explain the different concepts, comprehension activities, and tutorials at the end of the week in the form of interactive exercises. For practical work, the experiences were recorded in audiovisual format to facilitate understanding of the optical phenomena and complete the apprehension of the course. 22 video capsules were produced with durations of 2 to 8 minutes, depending on the concept explained. 17 PDF documents. 22 sets of comprehension questions and 7 sets of weekend Quiz. External resources to deepen the learners' knowledge are given in the bibliography section of the MOOC.

\section{EVALUATION OF THE OPTICAL PHYSICS MOOC}

\subsection{Evaluation of learners}

The evaluation as we proposed in this MOOC is done in three stages. The first step is a series of multiple-choice questions (MCQ) after each capsule. The learner can use two tests before displaying the correct answer. All questions were weighted to one point (formative assessment). The second step is an exercise (at the end of each week) which covers all of the capsules of the week ( 2 to 3 capsules per week). The weekly assessment has been set at $10 \%$ (summative assessment). We have programmed this MOOC for seven weeks that makes $70 \%$ of the total MOOC grade. The third stage is a set of exercises covering the entire course content at the 8th week, which is called the final evaluation week. The final assessment counts for the remaining $30 \%$.

\begin{tabular}{|l|c|c|c|}
\hline & $\begin{array}{c}\text { QCM } \\
\text { after } \\
\text { Capsules }\end{array}$ & $\begin{array}{c}\text { Week-end } \\
\text { Exercices }\end{array}$ & $\begin{array}{c}\text { Final } \\
\text { assessment }\end{array}$ \\
\hline $\begin{array}{l}\text { Number of } \\
\text { questions } \\
\begin{array}{l}\text { Approximate } \\
\text { Percentage (\%) }\end{array}\end{array}$ & 82 & 63 & 58 \\
\hline
\end{tabular}

Table 1: Total number of questions for the 3 parts (multiple choice questions, exercises, and the final evaluation).

During each week ( 7 weeks), we offer 19 series of multiplechoice questions (MCQ). Each series contains four or five questions after each capsule. Feedback notes follow all questions. At the end of each week-course, an exercise of 7 to 10 questions is proposed covering all the concepts presented during the week ( 2 to 3 capsules). The final evaluation encompasses three problems. Each problem has 10 to 20 questions. Table 1 gives the total number of questions for the three parts (multiple choice questions, exercises, and the final evaluation). Learners who have obtained an overall mark higher than $60 \%$ can have a certificate.

It should be noted that for the session 1 and students of the Faculty of Sciences of the UCA, this grade does not affect the grade of the module taught in face-to-face (it is the face-to-face exam that counts $100 \%$ of the module grade). For the second session of this MOOC, the teaching team is thinking of integrating the score of this MOOC in the calculation of the final grade in addition to the marks obtained in the face-to-face exam.

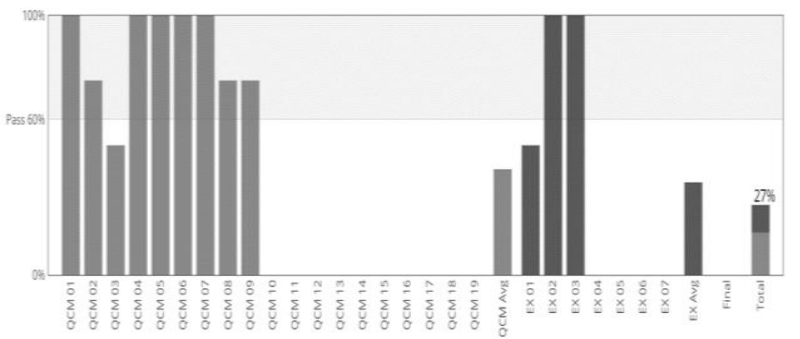

Figure 3: Progress of a student towards the end of week 3 of session 1, Spring 2019.

Monitoring can be personalized as shown in Figure 3. The teacher or a member of the pedagogical team can visualize at any time the progress of the realization of activities by learners. In the example in Figure 3, this is the progression of a student towards the end of week 3 . We can say that he is a diligent student.

\subsection{Content evaluation}

(1) The first step is the content evaluation by beta testers.

The MOOC was opened to beta testers 8 weeks before the start of the course. This operation consisted of checking the content, its online adaptation, its cognitive load, and related activities each week. Four Master students, three teachers from the physics department of the Semlalia Faculty of Sciences, and three external teachers compose the beta-testers team. Initially, this operation made it possible to detect some anomalies linked to the responses of Feedbacks and some syntactic or spelling errors. Secondly, this beta-test assured the validation of the content and its suitability for the university program.

(2) The second step is the evaluation of the content by the learners themselves.

The course being launched sequentially, week after week, the FAQ (Frequent Asked Questions) made it possible to feed the answers to the students' questions and comments as they went along the course. Until the closing of the MOOC, no complaints were made about the quality or content of the MOOC.

(3) The third step concerns the evaluation of the results of the students, from the SMP / S4 stream of the Semlalia Faculty of Sciences, who followed the MOOC compared to their mates who did not follow it.

\begin{tabular}{|l|l|l|l|l|}
\hline & $\begin{array}{l}\text { Students } \\
\text { who } \\
\text { followed } \\
\text { the MOOC } \\
\text { and did the } \\
\text { activities }\end{array}$ & $\begin{array}{l}\text { Students } \\
\text { who } \\
\text { followed } \\
\text { the MOOC } \\
\text { without } \\
\text { doing the } \\
\text { activities }\end{array}$ & $\begin{array}{l}\text { Students } \\
\text { who did not } \\
\text { follow the } \\
\text { MOOC }\end{array}$ & $\begin{array}{l}\text { Students } \\
\text { from the } \\
\text { SMP/S4 } \\
2019 \\
\text { promotion }\end{array}$ \\
\hline $\begin{array}{l}\text { Number } \\
\begin{array}{l}\text { Average } \\
\text { rating }\end{array}\end{array}$ & 36 & 169 & 316 & $\begin{array}{l}521 \\
9,3 / 20\end{array}$ \\
\hline
\end{tabular}

Table 2: Results of FSSM students who followed the MOOC compared to students who did not follow it.

Table 2 clearly shows that, although the number of students is limited, those who took the MOOC performed better on average. Moreover, those who followed the MOOC with the realization of the activities passed better their exam in face-toface. This shows the difference between taking a course by carrying out the activities and taking it without doing it. This observation alone cannot conclude that the only parameter that improved student performance is the monitoring of the MOOC, 
but we can admit that this is an important factor in this improvement.

From (1), (2), and (3), we can admit that the observations resulting from the three stages were sufficient to justify the quality of the MOOC in terms of content, layout, and improvement in student performance.

\section{CONCLUSION}

The MOOC of physical optics (MOOC UCA-002) is the first MOOC opened on the Moroccan digital platform. The other contents of the MUN platform, in 2019, were open by invitation for limited groups (SPOCs). It is a complete course that can be integrated easily into a hybrid-teaching device or a flippedclass pedagogy.

A good organization of the contents must be checked before the implementation, in progress, and at the end of the MOOC. This allows us to anticipate possible bad integrations. The beta test has shown great utility for our case. Also, the implementation of FAQs and the dissemination of content sequentially week by week makes it possible to make up for any unforeseen incident. Moreover, as in any teaching device, formative and summative evaluations are essential pieces in the learning process. In this MOOC, the operation once well planned was very simple to transform and then integrated into the platform.

We found that among the learners who took the course completely or in part, those who belong to the SMP stream of the FSSM improved their knowledge, which allowed them to better prepare for the face-to-face exam. We assume that this enabled a good number of these students to pass this module. In a second session scheduled for spring 2020, but extended until October 2020 for the Sars-COVID-19 pandemic, we will try to measure more finely the impact of this type of device in higher education and the possibility of switching to hybrid education in the case of the new Bachelor curricula. Another parameter to consider is the amount of time already observed in the second session in the monitoring process, caused essentially by the big number of subscribers on the MOOC. A good practice based on automatic smart monitoring/tutoring could reduce significantly the effort made by the pedagogical team to answer students' queries. This solution could be made by integrating Smart Chatbot in the platform which will constitute the next enhancement of the next (third) session of this MOOC.

\section{ACKNOWLEDGEMENTS}

The MOOC for physical optics was subsidized by a fund from the Ministry of National Education, Higher Education, Scientific Research, and Executive Training, following a national call for projects.

Cadi Ayyad University contributed by producing video capsules and educational scripting through its Center for Pedagogical Innovation (CIP).

Thanks to Ech-Chamikh El Maati and Bouhmaida Nouzha, professors at Cadi Ayyad University and members of the pedagogical committee of the MOOC team, for their contributions to the realization of the MOOC in physical optics. Thanks for Rachid Bendaoud, professor at Cadi Ayyad University, for reading and correcting this work in substance and form.

\section{REFERENCES}

Alario-Hoyos, C., Estévez-Ayres, I., Delgado Kloos, C., \& Villena-Román, J. (2017). From MOOCs to SPOCs... and from SPOCs to Flipped Classroom. In É. Lavoué, H. Drachsler, K. Verbert, J. Broisin, \& M. Pérez-Sanagustín (Eds.), Data Driven Approaches in Digital Education (Vol. 10474, pp. 347-354). Springer International Publishing. https://doi.org/10.1007/9783-319-66610-5_25

Bakki, A., Oubahssi, L., George, S., \& Cherkaoui, C. (2017). Approche et outils pour assister la scénarisation pédagogique des cMOOCs. 13.

Bates, A. T., \& Sangra, A. (2011). Managing technology in higher education: Strategies for transforming teaching and learning. John Wiley \& Sons.

Bédard, F., Pelletier, P., \& Le Clech, C. (2017). L’apprentissage hybride

http://collections.banq.qc.ca/ark:/52327/bs2785259

[Map].

Brita-Paja, J. L., Gregorio, C., Llana, L., Pareja, C., \& Riesco, A. (2019). Introducing MOOC-like methodologies in a face-toface undergraduate course: A detailed case study. Interactive Learning Environments, 27(1), 15-32. https://doi.org/10.1080/10494820.2018.1451345

Callejo Gallego, J., \& Agudo Arroyo, Y. (2018). MOOC: Valoración de un futuro. RIED. Revista Iberoamericana de $\begin{array}{llll}\text { Educación a } \quad \text { Distancia, } & 219 .\end{array}$ https://doi.org/10.5944/ried.21.2.20930

Chapman, S. A., Goodman, S., Jawitz, J., \& Deacon, A. (2016). A strategy for monitoring and evaluating massive open online courses. Evaluation and Program Planning, 57, 55-63. https://doi.org/10.1016/j.evalprogplan.2016.04.006

Ech-chamikh, E. maati, \& Mekkaoui Alaoui, I. (2013). EchChamikh, E., Mekkaoui Alaoui, I. (2013). Manuel de Physique, Optique II, SMP/SMC. Faculté des Sciences Semlalia. Université Cadi Ayyad Marrakech.

Gasevic, D., Kovanovic, V., Joksimovic, S., \& Siemens, G. (2014). Where is research on massive open online courses headed? A data analysis of the MOOC Research Initiative. The International Review of Research in Open and Distributed Learning, 15(5). https://doi.org/10.19173/irrodl.v15i5.1954

Guo, P. (2017). MOOC and SPOC, Which One is Better? Eurasia Journal Of Mathematics Science And Technology Education, 13(8), 5961-5967. https://doi.org/10.12973/eurasia.2017.01044a

Hudson, L., Kortuem, G., Wolff, A., \& Law, P. (2016). Smart Cities MOOC: Teaching citizens how to co-create smart cities. Proceedings of ICT for Sustainability 2016. ICT for Sustainability 2016, Amsterdam, the Netherlands. https://doi.org/10.2991/ict4s-16.2016.18

Idrissi Jouicha, A., Berrada, K., Bendaoud, R., Machwate, S., Miraoui, A., \& Burgos, D. (2020). Starting MOOCs in African University: The Experience of Cadi Ayyad University, Process, Review, Recommendations, and Prospects. IEEE Access, 8, 17477-17488. https://doi.org/10.1109/ACCESS.2020.2966762 
Jordan, K. (2014). Initial trends in enrolment and completion of massive open online courses. The International Review of Research in Open and Distributed Learning, 15(1). https://doi.org/10.19173/irrodl.v15i1.1651

McGreal, R., Kinuthia, W., \& Marshall, S. (2013). Open educational resources: Innovation, research and practice. Commonwealth of Learning (COL).

Peraya, D., Charlier, B., \& Deschryver, N. (2014). Une première approche de l'hybridation. Education \& Formation, e301,20 .

Pisha, B., \& Coyne, P. (2001). Smart From the Start: The Promise of Universal Design for Learning. Remedial and Special Education, 22(4), 197-203. https://doi.org/10.1177/074193250102200402

Schuwer, R., Gil Jaurena, I., Aydin, C. H., Costello, E., Dalsgaard, C., Brown, M., Jansen, D., \& Teixeira, A. (2015). Opportunities and Threats of the MOOC Movement for Higher Education: The European Perspective. The International Review of Research in Open and Distributed Learning, 16(6). https://doi.org/10.19173/irrodl.v16i6.2153

Vaughan, N. D., Cleveland-Innes, M. \& Garrison, D. R. (2013). Teaching in Blended Learning Environments. Published by au Press, Athabasca University ISBN 978-1-927356-47-0 